\title{
Evaluation of the anterior cervical angle of the uterus to predict spontaneous preterm birth
}

\author{
Bijay Sur, Sujata Misra*, Sanghamitra Dash
}

Department of Obstetrics and Gynecology, SCB Medical College, Cuttack, Odisha, India

Received: 09 May 2017

Accepted: 13 May 2017

\section{*Correspondence:}

Dr. Sujata Misra,

E-mail: drsujatamisra@gmail.com

Copyright: (C) the author(s), publisher and licensee Medip Academy. This is an open-access article distributed under the terms of the Creative Commons Attribution Non-Commercial License, which permits unrestricted non-commercial use, distribution, and reproduction in any medium, provided the original work is properly cited.

\begin{abstract}
Background: This prospective observational study was conducted to evaluate the anterior cervical angle (ACA) of the uterus by transvaginal sonography (TVS) and to determine the feasibility to predict spontaneous preterm birth (PTB). The duration of the study was from December 2014-December 2016.The participants included 100 pregnant women with singleton pregnancy who were asymptomatic. They were enrolled after excluding all known risk factors of preterm birth.

Methods: The ACA and cervical length were measured in all cases by transvaginal sonography either in the 1st trimester or 2nd trimester. All cases were followed and well documented with respect to the gestational age at delivery.

Results: There was a significant risk of preterm labour in women with cervical length $<2.5 \mathrm{~cm}$ in the 2 nd trimester with Odds Ratio $3.625, \mathrm{P}$ value $=0.001$, sensitivity $75 \%$ and specificity $79.31 \%$. The positive predictive value was $33.33 \%$ and negative predictive value $95.83 \%$. The false positive rate was $20.65 \%$ and false negative rate $25 \%$. The difference of mean cervical angle in women who delivered preterm and that of those who delivered at term, in the $1^{\text {st }}$ trimester (preterm group $114.2^{\circ} \mathrm{Vs}$ term group $93.0^{\circ}, \mathrm{P}<0.001$ ) and in the 2 nd trimester (preterm group $127.66^{\circ} \mathrm{Vs}$ term group $103.65^{\circ}, \mathrm{P}<0.001$ ) was significant. An ACA of $114.2^{\circ}$ in the 1 st trimester was associated with a risk of spontaneous preterm birth (P value 0.0065 , sensitivity $90 \%$ and specificity $80 \%$ ). An ACA of $127.66^{\circ}$ in 2 nd trimester was associated with a risk of spontaneous preterm birth (P value 0.0004 , sensitivity $80 \%$ and specificity $88.23 \%$ ).

Conclusions: Despite the limitations of a small sample size, the results suggest that the anterior cervical angle has potential as a new predictor of spontaneous preterm birth especially when measured in the 1st trimester.
\end{abstract}

Keywords: Anterior cervical angle, Preterm birth, Transvaginal sonography

\section{INTRODUCTION}

Preterm birth is the leading cause of neonatal morbidity and mortality worldwide. It accounts for $75 \%$ of neonatal deaths and $50 \%$ of long-term morbidity which is inversely related to the gestational age at birth. ${ }^{1}$ According to WHO, 2016 (Nov), an estimated 15 million babies are born too early every year and almost 1 million children die each year due to complications of preterm birth. ${ }^{2}$ In India, out of 27 million babies born every year (2010 data), 3.5 million babies born are premature. The effects of PTB extend beyond early infancy with substantial long-term consequences in late childhood and adult life. $^{3}$

Current prenatal screening protocols during the first and second trimesters, identify only approximately 55\% to $69 \%$ of cases of spontaneous preterm birth (PTB), respectively. ${ }^{4}$ The concept of an ultrasonic measurement of the anterior cervical angle (ACA) can be an additional predictor of spontaneous PTB. The patho-physiological principle is purely physical and follows the rules of 
gravity and trigonometry. With advancing pregnancy, the force of the pregnant uterus is shifted towards the cervix and depending on the angle of inclination, the cervical canal is either pressed shut in case of an acute angle or pressed open in case of an obtuse angle. This shift in cervical angle is used by one of the most effective interventions in preventing spontaneous PTB. ${ }^{4}$ This is a prospective observational study to evaluate the anterior cervical angle (ACA) measured by Transvaginal sonography (TVS) for the prediction of spontaneous preterm birth

\section{METHODS}

This prospective observational study was conducted on women with singleton pregnancy in the $1^{\text {st }}$ and $2^{\text {nd }}$ trimesters attending the OPD or admitted to Obstetrics and Gynecology Department, S.C.B. Medical College and Hospital, Cuttack.

\section{Exclusion criteria}

Multiple pregnancy, polyhydramnios, uterine anomalies, fibroids, h/o cervical excision treatment, rupture of membrane, uterine specific infections (chorioamnitis, bacterirua etc), cigarette smoking, illicit drug abuse, physical abuse, all other systemic illnesses. Number of cases were 100 .

All pregnant women with singleton pregnancy, recruited in this study, underwent transvaginal sonography to measure the anterior cervical angle and cervical length in the $1^{\text {st }}$ and $2^{\text {nd }}$ trimesters. (Anterior uterine wall was imaged, the internal and external cervical ora including the isthmus were identified and a line between them was drawn. A second line was drawn parallel to the lower aspect of the anterior uterine wall passing through the internal cervical os. The angle created by the two lines at the internal os was measured). They were followed up and the pregnancy outcome was documented. The co relation of preterm birth and term birth and its relation to the cervical angle was analyzed.

\section{RESULTS}

During the two years period (December 2014Dececember 2016) of this prospective study, 63 women of the 100 cases enrolled, delivered at term; while 37 women had preterm delivery. Of the women who delivered preterm, $50 \%$ were of the high socioeconomic group, $28.3 \%$ in the low socioeconomic group and $38.9 \%$ in the middle socioeconomic group. On analysing the relationship of maternal age to the incidence of preterm labour, it was seen that the highest incidence of preterm labour in the age group 25-30 years (45.7\%); while it was $26.4 \%$ in the $20-25$ age group and $25 \%$ in the $30-35$ years age group. The relationship of maternal height to preterm labour was analysed and it was inferred that the incidence of preterm labour was highest $(35.7 \%)$ in the group with a maternal height between $140 \mathrm{~cm}-150 \mathrm{~cm}$.It was $31.6 \%$ in the height group $>150 \mathrm{~cm}$ and $18.2 \%$ in height $<140 \mathrm{~cm}$.

The relation of history of preterm delivery to the risk of preterm labour was analysed.

It was seen that in $81.25 \%$ of the cases with history of prior preterm birth had preterm labour. Statistical analysis further showed the $\mathrm{P}$ value to be $<0.001$ and the Odds Ratio was 3.15 . The $95 \%$ Confidence interval was 1.9574-5.0693and $\chi^{2}$ was 20.056 (Table 1 ).

Table 1: Risk of preterm labour in relation to $\mathrm{H} / \mathrm{O}$ preterm birth.

\begin{tabular}{|c|c|c|c|c|c|}
\hline \multirow{2}{*}{$\begin{array}{l}\text { History of preterm } \\
\text { birth }\end{array}$} & \multicolumn{4}{|l|}{ Preterm labour } & \multirow{2}{*}{ Total } \\
\hline & No & $\%$ & Yes & $\%$ & \\
\hline No & 64 & 76.2 & 20 & 23.8 & 84 \\
\hline Yes & 3 & 18.75 & 13 & 81.25 & 16 \\
\hline \multirow[t]{2}{*}{ Total } & 67 & 67 & 33 & 33 & 100 \\
\hline & Value & df & $\begin{array}{l}\text { Asymp Sig. } \\
\text { (2-sided) }\end{array}$ & $\begin{array}{l}\text { Exact Sig. } \\
\text { (2-sided) }\end{array}$ & $\begin{array}{l}\text { Exact Sig. } \\
\text { (1-sided) }\end{array}$ \\
\hline Pearson Chi-Square & 20.056 & 1 & 0.000 & & \\
\hline Continuity Correction & 17.542 & 1 & 0.000 & & \\
\hline Likelihood Ratio & 19.182 & 1 & 0.000 & & \\
\hline Fisher's Exact Test & & & & 0.000 & 0.000 \\
\hline Relative risk 3.1500 & $95 \%$ CI $1.9574-5.0693$ & $\mathrm{P}$ value $<0.001$ & Odds Ratio 3.15 & & \\
\hline
\end{tabular}

Table 2 represents the relationship of cervical length measured in 2nd trimester by TVS scan of subjects with preterm labour. For the estimation of risks by cervical length in preterm labour, measured cervical length was divided into 2 groups i.e. cases (those whose $\mathrm{CL}<2.5 \mathrm{~cm}$ ) and controls (those whose $\mathrm{CL} \geq 2.5 \mathrm{~cm}$ ). There was a higher incidence of preterm labour $(75 \%)$ in cervical length $<2.5 \mathrm{~cm}$ than incidence $(20.68 \%)$ in cervical length $\geq 2.5 \mathrm{~cm}$. 
Table 2: Relation between $2^{\text {nd }}$ trimester cervical length and preterm labour.

\begin{tabular}{|c|c|c|c|c|c|c|}
\hline \multirow{2}{*}{\multicolumn{2}{|c|}{$2^{\text {nd }}$ trimester cervical length }} & \multicolumn{4}{|c|}{ Preterm Labour } & \multirow{2}{*}{ Total } \\
\hline & & No & $\%$ & Yes & $\%$ & \\
\hline \multicolumn{2}{|l|}{ Less than $2.5 \mathrm{~cm}$} & 2 & 25 & 6 & 75 & 8 \\
\hline \multicolumn{2}{|c|}{ More than equals to $2.5 \mathrm{~cm}$} & 46 & 79.3 & 12 & 20.7 & 58 \\
\hline \multicolumn{2}{|l|}{ Total } & 48 & 72.7 & 18 & 27.3 & 66 \\
\hline & Value & df & Asymp. Sig. (2-sided) & \multicolumn{2}{|c|}{ Exact Sig. (2-sided) } & Exact Sig. (1-sided) \\
\hline Pearson Chi-square & 10.455 & 1 & 0.001 & & & \\
\hline Continuity Correction & 7.896 & 1 & 0.005 & & & \\
\hline Likelihood Ratio & 9.210 & 1 & 0.002 & & & \\
\hline Fisher's Exact Test & & & & 0.004 & & 0.004 \\
\hline
\end{tabular}

Statistical analysis was done by Chi-Square tests which showed there was significant risk of preterm labour in subjects with $\mathrm{CL}<2.5 \mathrm{~cm}$ with Odds Ratio 3.625 (i.e. more than 3 times higher risk), $\mathrm{P}$ value 0.001 , Chi-Square $\left(\chi^{2}\right)=10.455$, Confidence Interval (CI) 1.905-6.898 and Relative risk 3.6250. $2^{\text {nd }}$ trimester cervical length cut-off level $<2.5 \mathrm{~cm}$ was predictor of spontaneous preterm birth with sensitivity $75 \%$ and specificity $79.31 \%$. Positive predictive value $33.33 \%$ and negative predictive value $95.83 \%$. The False positive rate was $20.65 \%$ and false negative rate $25 \%$.

Table 3: Relation between ACA in $1^{\text {st }}$ trimester and preterm labour.

\begin{tabular}{|c|c|c|c|c|c|c|c|}
\hline & & \multicolumn{2}{|c|}{ Number } & \multicolumn{2}{|c|}{ Mean } & Std. deviation & Std. Error Mean \\
\hline \multirow{2}{*}{$\begin{array}{l}\text { ACA in } 1^{\text {st }} \\
\text { trimester }\end{array}$} & No & \multicolumn{2}{|c|}{16} & \multicolumn{2}{|c|}{$93.038^{\circ}$} & 10.3589 & 2.5897 \\
\hline & Yes & \multicolumn{2}{|c|}{15} & \multicolumn{2}{|c|}{$114.213^{\circ}$} & 2.4089 & 0.6220 \\
\hline \multirow{2}{*}{\multicolumn{2}{|c|}{$\mathrm{ACA}$ in $1^{\text {st }}$ trimester }} & \multicolumn{2}{|c|}{ s PTL } & \multicolumn{2}{|c|}{ No s PTL } & \multirow{2}{*}{ Total } & \multirow{4}{*}{$\begin{array}{l}\mathrm{P} \text { value }=0.0065 \\
95 \% \text { Confidence Interval }(\mathrm{CI}) \\
2.7210-476.2989 \\
\text { Odds ratio (OR) } 36.00\end{array}$} \\
\hline & & $\mathrm{N}$ & $\%$ & $\mathrm{~N}$ & $\%$ & & \\
\hline \multicolumn{2}{|l|}{$<114.2^{\circ}$} & 2 & 20 & 8 & 80 & 10 & \\
\hline \multicolumn{2}{|l|}{$\geq 114.2^{\circ}$} & 9 & 90 & 1 & 10 & 10 & \\
\hline
\end{tabular}

Table 4: Relation between ACA in $2^{\text {nd }}$ trimester and preterm labour.

\begin{tabular}{|c|c|c|c|c|c|c|c|}
\hline Preterm lab & & \multicolumn{2}{|c|}{ Number } & \multicolumn{2}{|c|}{ Mean } & Std. deviation & Std. Error Mean \\
\hline \multirow{2}{*}{$\begin{array}{l}\mathrm{ACA} \text { in } 2^{\text {nd }} \\
\text { trimester }\end{array}$} & No & \multicolumn{2}{|c|}{51} & \multicolumn{2}{|c|}{$103.649^{\circ}$} & 14.0096 & 1.9617 \\
\hline & Yes & \multicolumn{2}{|l|}{18} & \multicolumn{2}{|c|}{$127.661^{\circ}$} & 6.6117 & 1.5584 \\
\hline \multirow{2}{*}{\multicolumn{2}{|c|}{$\mathrm{ACA}$ in $2^{\text {nd }}$ trimester }} & \multicolumn{2}{|c|}{ sPTL } & \multicolumn{2}{|c|}{ No s PTL } & \multirow{2}{*}{ Total } & \multirow[t]{2}{*}{$\mathrm{P}^{\prime}$ value $=0.0004$} \\
\hline & & $\mathrm{N}$ & $\%$ & $\mathrm{~N}$ & $\%$ & & \\
\hline \multicolumn{2}{|l|}{$<127.66^{\circ}$} & 4 & 11.8 & 30 & 88.2 & 34 & \multirow{2}{*}{$\begin{array}{l}95 \% \text { Confidence Interval (CI) } \\
4.6329-194.2615 \\
\text { Odds ratio (OR) } 30.00\end{array}$} \\
\hline \multicolumn{2}{|l|}{$\geq 127.66^{\circ}$} & 8 & 80 & 2 & 20 & 10 & \\
\hline
\end{tabular}

There was significant difference of mean ACA between peterm group and term group, $\left(114.2^{\circ}\right.$ vs $\left.93.0^{\circ}\right)$. The incidence of spontaneous preterm birth was more in $1 \mathrm{st}$ trimester $\mathrm{ACA} \geq 114.2^{\circ}$ (i.e. 90\%) and statistical analysis shows this angle was associated with risk of spontaneous PTL with $\mathrm{P}$ value $=0.0065,95 \%$ Confidence Interval $(\mathrm{CI})$ 2.7210-476.2989andOdds Ratio 36.00 (Table 3).

There was significant difference of mean ACA between peterm group and term group, $\left(127.66^{\circ}\right.$ vs $\left.103.65^{\circ}\right)$. The incidence of spontaneous preterm birth was more in ACA $\geq 127.66^{\circ}$ (80\%).On further analysing the data it was found that the $2^{\text {nd }}$ trimester $\mathrm{ACA} \geq 127.66^{\circ}$ was associated with significant risk of spontaneous PTL with ' $\mathrm{P}$ ' value 0.0004, 95\% Confidence Interval (CI) 4.6329194.2615andOdds Ratio 30.00 (Table 4).

\section{DISCUSSION}

Across 184 countries, the rate of preterm birth ranges from $5 \%$ to $18 \%$ of babies born. ${ }^{2}$ Globally it is estimated that $11.1 \%$ of births are preterm and being born preterm is the direct cause of $27 \%$ of the neonatal deaths ${ }^{3 .}$ During 
the study period, (December 2014-December 2016), the institutional incidence of preterm births was $28.02 \%$ and the incidence of preterm births in our study group was $37 \%$. There was an increased incidence of preterm births in high socio-economic groups but statistically no significant causal association between preterm birth and socio-economic status. There was higher incidence of preterm labour $(81.25 \%)$ in subjects with history of preterm birth as compared to lower incidence $(23.80 \%)$ in subjects without history of preterm birth. Chi-Square Tests of independence revealed the Pearson Chi-Square $\left(\chi^{2}\right)$ 20.056; 95\% Confidence interval (CI) 1.9574-5.0693, and $\mathrm{P}$ value $<0.001$ which signified that there was a significant causal effect of history of prior preterm birth with preterm labour in the subsequent pregnancies with Odds Ratio (OR) 3.1500 .

From statistical analysis, it concluded that the history of prior preterm birth is a risk factor for preterm labour in subsequent pregnancies with $\mathrm{P}$ value $<0.001$, sensitivity $81.25 \%$ and specificity $76.19 \%$. Bloom SL et al, observed that the risk of recurrent preterm delivery for those whose $1^{\text {st }}$ delivery was preterm, is increased by three-fold, compared with women whose $1^{\text {st }}$ delivery reached term. Almost $1 / 3^{\text {rd }}$ of women whose first two deliveries were preterm, delivered preterm in their $3^{\text {rd }}$ pregnancies. $^{5}$ Yamashita $\mathrm{M}$ et al, have reported that the risk factors for recurrence included multiple previous spontaneous PTB (adjusted odds ratio (aOR): 2.26; 95\% confidence interval (CI): $1.19-4.30 ; \mathrm{P}=0.013$ ), as compared to no previous term birth (aOR: 2.08; 95\% CI: 1.24-3.49; $\mathrm{P}=0.005$ ). ${ }^{6}$ Mazaki-Tovi $\mathrm{S}$ et al have opined that patients with a history of an indicated preterm birth are at risk not only for recurrence of this subtype, but also for spontaneous preterm birth. $^{7}$

In the study, the second trimester cervical length cut-off level $<2.5 \mathrm{~cm}$ was predictor of spontaneous preterm birth with sensitivity $75 \%$ and specificity $79.31 \%$. Positive predictive value $33.33 \%$ and negative predictive value $95.83 \%$. The False positive rate was $20.65 \%$ and false negative rate $25 \%$. According to Banicevic AC et al, the incidence of high premature birth (defined as birth before 36.6 weeks) was $50 \%$ in patients with cervical length bellow $15 \mathrm{~mm}$. In the group of patients with cervical length up to $25 \mathrm{~mm}$ the premature risk incidence was $10.52 \pm 0.05 .^{8}$

According to Boelig RC et al, women with a short CL did not differ from women with normal CL with respect to demographic variables or mean number of risk factors (4.20 \pm 2.11 versus $3.52 \pm 1.97, p=0.23)$, but they did deliver at a significantly earlier gestational age $(25.0 \pm 1.1$ versus $34.6 \pm 3.1$ weeks, $\mathrm{p}<0.01$ ). The distribution of the presentation of SPTB was different in women with a short versus normal CL $(\mathrm{p}<0.01) .{ }^{9}$ Iams JD, Goldenberg RL, Meis PJ, et al have reported that when the length is below $20 \mathrm{~mm}$ there is increased risk and treatment should be considered. Cervical length $<20 \mathrm{~mm}$ at 24 weeks has sensitivity of $23 \%$, specificity of $97 \%$ and positive predictive value of $26 \%$ for PTB before 35 weeks in a population with a PTB rate of $4.3 \% .{ }^{10}$

There was significant difference of mean angle between women who delivered preterm and that of those who delivered at term (preterm group 114.2 ${ }^{\circ} \mathrm{Vs}$ term group $93.0^{\circ}$ ) and a significance association between ACA and spontaneous preterm birth. The ACA of $114.2^{\circ}$ in $1^{\text {st }}$ trimester yielded a risk of spontaneous preterm birth with $\mathrm{P}=0.0065$, false positive rate $18.18 \%$. According to $\mathrm{N}$. Sochacki-W 'ojcicka et al, there was a significant difference between the median ACA in the first trimester of women who delivered preterm and that of those who delivered at term (preterm group, $115.5^{\circ}$ vs controls, 85०; $P=0.0002)$. A linear regression analysis suggested that the ACA increased with advancing gestation $(\mathrm{P}=0.0001)$. As an isolated marker, the ACA yielded an estimated detection rate for spontaneous PTB of $61.1 \%$ in the first trimester with a false-positive rate of $10 \% .^{11}$

The study showed a significant difference of mean ACA in $2^{\text {nd }}$ trimester between women who delivered preterm and that of those who delivered at term (preterm group $127.66^{\circ} \mathrm{Vs}$ term group $103.65^{\circ}$ ) and a significant association between ACA and spontaneous preterm birth. According to N. Sochacki-W ojcicka et al, there was a significant difference between the median ACA in the second trimester of women who delivered preterm and that of those who delivered at term (preterm group, $126^{\circ}$ vs controls, $\left.91.5^{\circ} ; \mathrm{P}<0.0001\right)$. A linear regression analysis suggested that the ACA increased with advancing gestation $(\mathrm{P}=0.0001)$. As an isolated marker, the ACA yielded an estimated detection rate for spontaneous PTB of $66.7 \%$ in the second trimester with a false-positive rate of $10 \% .{ }^{11}$ Dziadosz $\mathrm{M}$ et al too have reported that in gestations between 16 0/7-23 6/7 weeks, the uterocervical angle of $\geq 95$ degrees was significantly associated with spontaneous preterm birth <37 weeks with sensitivity of $80 \%$ ( $\mathrm{P}<0.001$; confidence interval, $0.70-0.81$; negative predictive value, $95 \%$ ). Uterocervical angle of $\geq 105$ degrees predicted spontaneous preterm birth <34 weeks with sensitivity of $81 \%$ ( $\mathrm{P}<0.001$; confidence interval, $0.72-0.86$; negative predictive value, $99 \%) .^{12}$

\section{CONCLUSION}

100 asymptomatic women with a single term pregnancy without any risk factors for preterm birth were included in the study. The anterior cervical angle and cervical length were measured in all cases by transvaginal sonography either in the 1 st trimester or $2^{\text {nd }}$ trimester. All cases were followed and all documents were recorded specially focusing on preterm labour (spontaneous/indicated) and other causes of preterm birth developed later causing late exclusion from the study. Statistical analysis showed that there was no significant risk associations of maternal age, maternal height and socio-economic status with preterm birth. There was a significant risk of preterm labour in women with cervical 
length $<2.5 \mathrm{~cm}$ in the 2nd trimester. A significant difference of mean angle between women who delivered preterm and that of those who delivered at term in both 1st trimester (preterm group 114.2 ${ }^{\circ}$ Vs term group 93.0 $0^{\circ}$ ) and $2^{\text {nd }}$ trimester (preterm group $127.66^{\circ} \mathrm{Vs}$ term group $103.65^{\circ}$ ) was noted. The ACA of $114.2^{\circ}$ in $1^{\text {st }}$ trimester was associated with a risk of spontaneous preterm birth and an $\mathrm{ACA}$ of $127.66^{\circ}$ in $2^{\text {nd }}$ trimester was associated with a risk of spontaneous preterm birth.

The results suggest that the anterior cervical angle has potential as a new predictor of spontaneous preterm birth especially when measured in the $1^{\text {st }}$ trimester. Detection rates may be improved if combined with other parameters such as cervical length, maternal characteristics and obstetric history. This would be of great help and importance in the prediction and hence prevention of PTB.

Funding: No funding sources Conflict of interest: None declared

Ethical approval: The study was approved by the Institutional Ethics Committee

\section{REFERENCES}

1. A South Asian Perspective. Arias Practical Guide to high-risk pregnancy and delivery. Editors Arias F, Bhide A, Arulkumaran S, Damania K, Daftary S. $\left(4^{\text {th }}\right.$ Ed); 2015 Chapter 8:135.

2. WHO Fact sheet Reviewed November 2016Avaialble from: http://www.who.int/mediacentre/factsheets/fs363/en.

3. National Health Portal Gateway to authentic health information. Available from: www.nhp.gov.in

4. Sochacki-Wojcicka N, Wojcicki J, Bomba-Opon 'D, Wielgos M. Anterior cervical angle as a new biophysical ultrasound marker for prediction of spontaneous preterm birth. Ultrasound Obstet Gynecol. 2015;46:376-9.
5. Bloom SL. Recurrence of preterm birth in single term and twin pregnancies. Obstet Gynecol. 2001;98:379.

6. Yamashita M, Hayashi S, Endo M, Okuno K, Fukui $\mathrm{O}$, Mimura $\mathrm{K}$ et al. Obstetric research collaborative in Osaka (ORCO). J Obstet Gynaecol Res. 2015;41(11):1708-14.

7. Mazaki-Tovi S, Romero R, Kusanovic JP, Erez O, Pineles BL, Gotsch F et al. Recurrent preterm birth. Semin Perinatol. 2007;31(3):142-58.

8. Banicevic AC, Popovic M, Ceric A. Cervical length measured by transvaginal ultrasonography and cervicovaginal infection as predictor of preterm birth risk. Acta Inform Med. 2014;22(2):128-32.

9. Boelig RC, Orzechowski KM, Berghella V. Cervical length, risk factors, and delivery outcomes among women with spontaneous preterm birth. J Matern Fetal Neonatal Med. 2016 Sep;29(17):2840-4.

10. Iams JD, Goldenberg RL, Meis PJ, Mercer BM, Moawad A, Das A et al. The length of the cervix the risk of spontaneous premature delivery. N Engl J Medicine. 1996;44(3):292-4.

11. Sochacki- Wójcicka N, Wojcicki J, Bomba- Opon D, Wielgos M. Anterior cervical angle as a new biophysical ultrasound marker for prediction of spontaneous preterm birth. Ultrasound Obstet Gynecol. 2015;46(3):377-8.

12. Dziadosz M, Bennett TA, Dolin C, Honart AW, Pham A, Lee SS et al. Uterocervical angle: a novel ultrasound screening tool to predict spontaneous preterm birth. Am J Obstet Gynecol. 2016;215(3):376.e1-7.

Cite this article as: Sur B, Misra S, Dash S.

Evaluation of the anterior cervical angle of the uterus to predict spontaneous preterm birth. Int $\mathrm{J}$ Reprod Contracept Obstet Gynecol 2017;6:2323-7. 